

\title{
Derechos humanos, democracia y bloqueo: la visión de Rafael Correa acerca de las relaciones políticas entre los Estados Unidos y Cuba
}

\section{Human rights, democracy and embargo: Rafael Correa's vision of political relations between the United States and Cuba}

Dan Abner Barrera Rivera

\section{Resumen}

El propósito de este artículo es analizar el papel desarrollado por Rafael Correa en las relaciones políticas entre los gobiernos de los Estados Unidos y Cuba. El expresidente ecuatoriano aborda los temas de los derechos humanos y la democracia en el contexto del bloqueo que sufre Cuba desde hace casi seis décadas. Para hacer la investigación se recurrió al estudio de diez videos en los cuales Correa trata esos contenidos; siete de ellos son entrevistas y los otros tres son conferencias. A partir de los ejes principales (derechos humanos, democracia y bloqueo) se procedió a comparar las alocuciones, relacionar las semejanzas y profundizar en las ideas; luego se hizo la hermenéutica profunda del texto (videos) dentro del contexto de la propia entrevista (a veces controversial y otras veces más fraternal); al final se sistematizó el pensamiento del expositor siguiendo el orden cronológico de sus presentaciones. También se usaron fuentes bibliográficas (históricas, biográficas y filosóficas) de escritores autorizados, con el propósito de respaldar algunas de las ideas desarrolladas. Algunas de las conclusiones son: no es posible analizar con seriedad el sistema político cubano si se ignora el bloqueo económico, comercial y financiero que sufre la Isla; en Cuba tienen un sistema político socialista, donde desarrollan una democracia participativa; el bloqueo es una de las mayores violaciones a los derechos humanos de toda una nación; y la oposición y rechazo al bloqueo se hace por una cuestión de respeto al derecho internacional y no por simpatías políticas con el gobierno cubano. Este artículo es solo una aproximación exploratoria sobre el tema, que invita a profundizar en él.

1 Licenciado en Estudios Latinoamericanos; Licenciado en Teología; Máster en Derechos Humanos; realizó estudios de posgrado en Ciencias Políticas. Académico del IDELA, Universidad Nacional, Costa Rica. Peruano-costarricense. 
Palabras claves: Democracia, derechos humanos, bloqueo, Cuba, Estados Unidos

\section{Summary}

The purpose of this article is to analyze the role played by Rafael Correa in the political relations between the governments of the United States and Cuba. The former Ecuadorian president addresses the issues of human rights and democracy in the context of the Cuban Embargo that has endured for almost six decades. The present research was carried out by studying ten videos in which Correa dwells on these subjects; seven videos were interviews and the other three conferences. Considering the main subject axes (human rights, democracy and embargo) we proceeded to compare the allocutions, relate similarities and deepen the ideas; next, in-depth hermeneutics of the text (videos) were made within the context of the interview itself (sometimes controversial and other times more fraternal); finally, the exhibitor's thinking was systematized following the chronological order of his presentations. Bibliographic sources (historical, biographical and philosophical), from authorized writers, were also used to sustain some of the developed ideas. Some of the conclusions are: it is impossible to seriously analyze the Cuban political system without accounting for the economic, commercial and financial embargo suffered by the Island; Cuba possesses a socialist political system wherein a participatory democracy has developed; the embargo is effectively one of the greatest human rights violations of an entire nation; and, the opposition and rejection of the embargo stems from a matter of respect for international law and not due to political sympathies with the Cuban government. This article merely constitutes an exploratory approach on the subject matter and invites to deeper inquire.

Keywords: Democracy; Human rights; Embargo; Cuba; United States.

\section{Introducción}

Sobre el tema de los derechos humanos en relación con Cuba se ha escrito bastante, y la mayor parte ha sido hecha desde los medios de comunicación, cuya posición generalizada ha sido que, en Cuba no se respetan los derechos humanos y no hay democracia; es una sentencia categórica que ha sido normalizada por grandes sectores políticos y, cuando alguien ha dicho lo contrario, se ha tratado de silenciarlo o desacreditarlo. Nikolai S. Leonov plantea:

La prensa occidental que inculpa a Cuba de violar derechos humanos, no ha podido presentar ante la opinión pública ni una sola vez imágenes de manifestaciones disueltas con chorros de agua en las calles ni destacamentos policiacos blindados con escudos, ni de perros entrenados, prestos a atacar a la gente. Ninguna de esas escenas, comunes en países que se autoproclaman democráticos, se ven jamás en Cuba. (2015, p. 295)

Esa posición generalizada sobre Cuba responde, entre otras causas, a la visión occidental homogénea y hegemónica que ha sido impuesta respecto a lo que se 
entiende por democracia y derechos humanos. Tampoco se permiten voces diferentes a la voz dominante que expliquen la realidad social, económica y política que vive Cuba desde el triunfo de la revolución en 1959. La visión hegemónica cuando habla de democracia y de derechos humanos en Cuba, invisibiliza que ese país resiste y enfrenta un bloqueo económico, comercial y financiero impuesto por los Estados Unidos, cerca ya de sesenta años. La propia voz de Cuba ha sido aislada y acallada. Frei Betto dice que Cuba es un país "que es isla tres veces": por la geografía, por el bloqueo y por ser el único en la historia de Occidente que ha optado por el socialismo (2019, párr.11). Expone Ramonet que contra Cuba hay una uniformidad mediática que aplasta toda diversidad, censura cualquier expresión divergente y sanciona a los autores disidentes; el sistema capitalista es represivo, porque amordaza la libertad de expresión y reprime las voces diferentes; es un "sistema que no acepta la contradicción por muy argumentada que sea. Un sistema que establece una "verdad oficial" y no tolera la transgresión. Semejante sistema tiene un nombre, se llama: "tiranía" o "dictadura"” (2018, p. 799).

Este artículo busca exponer la voz de un tercer actor, se trata de Rafael Correa Delgado, quien durante los años que fungió como presidente de Ecuador (20072017), asumió una posición sui géneris sobre el tema de la democracia y los derechos humanos en Cuba y, lo hizo desde una perspectiva opuesta a la visión dominante. Siempre que lo abordó, tomó en cuenta el papel que el bloqueo juega en esa situación. Formalmente, el bloqueo total contra Cuba se implantó por parte de los Estados Unidos el 7 de febrero de 1962, y desde esa fecha hasta ahora, ningún presidente de América Latina ni de derecha ni de izquierda había asumido un papel político internacional constante, en defensa del derecho internacional y por lo tanto, en contra de la política exterior ejercida por el gobierno de los Estados Unidos hacia Cuba. Rafael Correa cada vez que dio declaraciones, conferencias y entrevistas se amparó en el derecho internacional para defender el derecho de Cuba a la soberanía, independencia y autonomía. Este es un caso inédito en la historia política de América Latina.

Pero las ideas expuestas por Correa respecto al bloqueo de los Estados Unidos contra Cuba no se encuentran en revistas o libros; lo poco que existe por escrito está en algunos periódicos con titulares escuetos y adversos que no se ajustan a la realidad; tergiversan los hechos, y no permiten un estudio amplio y serio. El pensamiento de Correa hay que buscarlo en otras partes; está acopiado en varias decenas de videos, que son parte de los "nuevos" registros orales de esta era digital, que aumentan y se almacenan rápido en la internet.

Los criterios para seleccionar los videos fueron: 1 ) que no sean videos editados (es decir que no tengan recortes o acomodos); 2) que sean entrevistas, conferencias 
de prensa o disertaciones del propio Rafael Correa (las ideas en la voz del protagonista); 3) que aborden el tema en cuestión a partir de tres ejes: el bloqueo de los Estados Unidos a Cuba, los derechos humanos y la democracia; y 4) que las ideas sean suficientemente extensas para poder ser estudiadas.

Para exponer el pensamiento de Rafael Correa sobre esos temas se procedió primero al estudio minucioso de las distintas audiencias donde él desarrolla los contenidos; luego de observaron veintitrés videos, y se escogieron diez, de los cuales siete son entrevistas y tres son discursos; en tercer lugar, se realizó el estudio comparativo de las alocuciones, para buscar relaciones de semejanzas, contradicciones o ampliación de las ideas; en un cuarto momento, se hizo la hermenéutica del texto oral (de los diez videos) y se tomó en cuenta el contexto y las circunstancias en las que se desarrollan las ideas; y, en quinto y último lugar, se organizó y sistematizó el pensamiento del protagonista con el objetivo de que mantuviera un orden lógico a la vez que cronológico (las fechas de las disertaciones de Rafael Correa abarcan de 2007 al 2017).

Correa es un economista que ingresó a la política procedente de la academia; llegó con la experiencia del ejercicio docente en la universidad y los aires frescos de haber hecho estudios de posgrado (maestría y doctorado) en universidades de los Estados Unidos y Europa; es decir, arribó a la política sin haber tenido un recorrido político partidario tradicional (pasó de las aulas a las plazas públicas). Su aparición en la política mostró que era un personaje con amplio conocimiento de la realidad y de la historia de América Latina. Algunos sectores de la prensa lo han catalogado de ser un político polémico y controversial.

Aunque en algunas ocasiones Correa ha expresado que la nueva izquierda latinoamericana a la que él se adscribe, no es anti nada, o sea, no es anti capitalista, anti norteamericana o anti imperialista, sino, pro dignidad, pro soberanía, pro justicia social, pro el buen vivir (U.S. Department of State, jun. 2010); sin embargo las entrevistas y disertaciones que aquí se estudian, muestran que su postura latinoamericana y su posición con respecto a Cuba, contienen una perspectiva antimperialista y frontal contra los Estados Unidos.

\section{Los Estados Unidos y el bloqueo a Cuba}

En una entrevista concedida al sacerdote Frei Betto en 1985, que se convirtió en el libro Fidel y la religión (1985), Fidel Castro expresó que el gobierno cubano entendía el costo que significaba para otros presidentes latinoamericanos ir a Cuba. Quienes intentaban hacerlo se exponían a recibir alguna sanción económica por parte del gobierno de los Estados Unidos. Visitar Cuba era un acto de rebeldía, 
independencia y soberanía. Habían pasado más de dos décadas del triunfo de la Revolución Cubana y muchos gobernantes habían escuchado de los logros sociales obtenidos por Cuba en educación, salud, mortalidad infantil, esperanza de vida, deporte, artes, seguridad ciudadana, misiones internacionales, participación popular, etcétera, y, que en su condición de presidentes, deseaban ir a la Isla para estrechar relaciones diplomáticas entre gobiernos, conocer de cerca esas políticas sociales y tratar de implementar algunos programas similares en sus países; pero, a pesar de tener esa investidura, no les era posible. De alguna manera, también estaban bloqueados por los Estados Unidos. Fidel Castro había expresado lo siguiente:

Porque no creas que cualquier jefe de Estado se atreve a visitar a Cuba, no creas que cualquier político se atreve a visitar a Cuba, puesto que jefes de Estado y políticos tienen que tomar muy en consideración lo que piensa Estados Unidos, y muchos de ellos tienen en cuenta eso, temen represalias económicas, políticas, temen disgustar a Estados Unidos, o porque necesitan alguna ayuda de ellos, o algún crédito en el Banco Mundial, en el Banco Interamericano, o deben negociar con el Fondo Monetario. (Betto, 1985, p. 318)

Por varias décadas eso fue así, pero con la elección de algunos presidentes de izquierda a finales de los años noventa la situación cambió y, el temor a las represalias de los Estados Unidos quedó en el pasado. Entre esos presidentes estuvieron Hugo Chávez Frías, Luiz Inácio da Silva, Néstor Carlos Kirchner, Evo Morales Ayma, Rafael Correa Delgado, Cristina Fernández, Daniel Ortega Saavedra, Tabaré Vázquez Rosas, José Mujica Cordano, Dilma Rousseff, Nicolás Maduro Moro entre otros. Algunos de ellos incluso se mostraban desafiantes ante el papel ejercido por el gobierno de los Estados Unidos en la región; el caso más conocido fue el de Hugo Chávez, quien no solamente solía visitar Cuba y reunirse con Fidel Castro para juntos elaborar propuestas latinoamericanistas y antimperialistas para la región, como fueron los casos de Telesur, ALBA TCP, Petrocaribe, UNASUR, Misión Milagro, etcétera, sino que, desde cualquier tribuna internacional, aprovechaba para denunciar la hegemonía y prepotencia de los Estados Unidos en América Latina y en otras partes del mundo; su discurso en la Asamblea de la Organización de las Naciones Unidas (ONU) contra el presidente George W. Bush el 2006 es revelador. Algunos de sus párrafos dicen:

Ayer vino el Diablo aquí, ayer estuvo el Diablo aquí, en este mismo lugar. ¡Huele a azufre todavía esta mesa donde me ha tocado hablar! Ayer señoras, señores, desde esta misma tribuna el Señor presidente de los Estados Unidos, a quien yo llamo "El Diablo", vino aquí hablando como dueño del mundo. Un psiquiatra no estaría de más para analizar el discurso de ayer del presidente de los Estados Unidos. Como vocero del Imperialismo vino a dar sus recetas para tratar de mantener el actual esquema 
de dominación, de explotación y de saqueo a los pueblos del mundo. (Chávez, 2006, párr. 5)

Aunque las distintas administraciones de los Estados Unidos siempre trataron de impedir que se conocieran los logros sociales de Cuba y el gobierno cubano tampoco exhibía lo que hacía, el mundo sabía que en esa Isla se habían gestado cambios importantes. A diferencia de la realidad de los países capitalistas, donde había aumentado la pobreza, el desempleo, las injusticias y las desigualdades, Cuba se había convertido en ejemplo para América Latina, y sus conquistas sociales fueron reconocidas por organismos internacionales como la Organización Panamericana de la Salud (OPS), el Fondo de las Naciones Unidas para la Infancia (UNICEF), la Organización de las Naciones Unidas para la Educación, la Ciencia y la Cultura (abreviado como UNESCO) entre otras. Al cierre del año 2018, el Banco Mundial al que no se le puede atribuir de ser una organización comunista informó que "el sistema educativo cubano es el mejor de América Latina" (El Caminante, 2018, párr. 1).

A pocos meses del triunfo de la Revolución Cubana en 1959, los batistianos que huyeron a Miami crearon con el beneplácito del gobierno de los Estados Unidos, una gran industria contrarrevolucionaria (que les produce dinero) que persiste hasta hoy (Escalante, 2018), la cual se valió de todo tipo de formas para derrotar la Revolución; lo intentó por casi sesenta años, sin lograrlo. Entre los métodos empleados privilegiaron las acciones terroristas, las cuales "trajeron como consecuencias la muerte de 3478 personas, y resultaron mutiladas e incapacitadas 2099" (Varios, 2003, p. 279).

La bacanal ideológica realizada desde Miami contra Cuba no tiene parangón en la historia; es una industria cultural enorme que produce libros, revistas, películas, documentales, premios, concursos, congresos; posee canales de televisión, programas de radio y prensa plana, todo esto con cobertura internacional y, opera sobre la base de la calumnia, la tergiversación de los hechos y la mentira. En una situación así disentir con esa forma de ver el proceso revolucionario cubano, es exponerse a ser acusado de defender la "dictadura cubana". En décadas recientes, incluso se hizo costumbre en América Latina que, cada vez que había elecciones en algún país, los candidatos que no pertenecían a los partidos de derecha eran interrogados por los medios de prensa acerca de su posición frente a Cuba; para ser aceptados como candidatos, debían confesar púbicamente que Cuba era una dictadura; eso era suficiente para que continuaran en la carrera electoral. Hoy los medios hacen lo mismo con los candidatos de izquierda en cualquier país, pero ahora les preguntan por su posición u opinión respecto al gobierno de Venezuela. 


\section{La ONU y el bloqueo a Cuba}

A diferencia de los presidentes de derecha que solo reconocen en privado las conquistas sociales de Cuba (y algunos incluso, exhiben como un trofeo, en círculos más íntimos sus fotos con Fidel Castro), los presidentes de izquierda solían hacerlo en público, pero lo hacían con cierta timidez. Sin embargo, ninguno ha tenido el valor, la claridad y los argumentos suficientes para exponer su posición respecto a la situación de Cuba, aun a sabiendas de lo que significa el bloqueo para esa nación. Con el actual gobierno de Donald Trump, este ha sido recrudecido. Cifras recientes revelan lo siguiente:

Los daños acumulados por el bloqueo durante casi seis décadas de su aplicación alcanzan la cifra de 933 mil millones 678 mil dólares, tomando en cuenta la depreciación del dólar frente al valor del oro en el mercado internacional. A precios corrientes, el bloqueo ha provocado perjuicios cuantificables por más de 134 mil 499 millones 800 mil dólares. (Informe de Cuba, 2018, p. 55)

Como puede verse, se trata de una situación flagrante de violación de los derechos humanos de toda una nación, la cual se hace a vista de todo el mundo y, aunque cada año la Asamblea General de la ONU vota por amplia mayoría para que se levante el bloqueo (el 2018 fue la vigésima séptima vez consecutiva de esa votación), el gobierno de los Estados Unidos hace caso omiso a esa demanda. En la ONU las votaciones son públicas; con excepción de Israel, que es aliado incondicional de los Estados Unidos, las demás delegaciones expresan abrumadoramente su rechazo a la política exterior de los Estados Unidos hacia Cuba. Una vez concluida la Asamblea, ninguno de los gobiernos que vota contra el bloqueo vuelve a referirse al tema (tampoco tienen la obligación de hacerlo), ellos cumplen con participar cada año en la tribuna de la ONU.

A pesar de la demanda de la ONU contra los Estados Unidos para que ponga fin al bloqueo y del reconocimiento de varias organizaciones internacionales de los logros sociales en Cuba, el mundo ha naturalizado los costos humanos, sociales, materiales y económicos producidos durante estas seis décadas. Sobre la violación a los derechos humanos de toda una nación no se escuchan voces de protesta de otros países, ni reclamos o denuncias de alguna organización no gubernamental que trabaja en derechos humanos; por el contrario muchas de estas son instrumentalizadas por los Estados Unidos con el objetivo de agredir a Cuba. Tampoco ha habido algún pedido por parte de la Organización de Estados Americanos (OEA) contra el bloqueo y, lo que es peor, la OEA, incluso se suma a la política injerencista de los Estados Unidos contra Cuba (el papel que desarrolla Luis Almagro actual Secretario General de la OEA en contra de los procesos democráticos populares 
de América Latina así lo evidencia). Por su parte, los grandes medios de comunicación se encargan de desinformar sobre el tema, y en las universidades otrora espacios de análisis sobre la realidad de América Latina cada vez que se habla de Cuba, se ignora lo que significa el bloqueo y, se repiten los mismos estribillos que han normalizado los medios de comunicación contra la Revolución Cubana.

Cuando se trata de estar al servicio de los intereses de los Estados Unidos en la región, la mayoría de los presidentes de derecha se apresta a organizarse y ponerse a disposición de las directrices de Washington; ese es el caso del llamado Grupo de Lima, creado el 8 de agosto de 2017, con propósitos injerencistas en el proceso político bolivariano de Venezuela; está conformado por Argentina, Brasil, Canadá, Chile, Colombia, Costa Rica, Guatemala, Honduras, México, Panamá, Paraguay y Perú. Con la elección de presidente Andrés Manuel López Obrador en México, el grupo ha tenido una baja sensible, porque López ha dicho que México rechaza la política injerencista del Grupo de Lima sobre Venezuela y ha asegurado que mantendrá relaciones con Caracas. La mayoría de los países integrantes del Grupo de Lima tiene grandes problemas sociales, cuyos datos respecto a desempleo, aumento de la pobreza, feminicidios, violaciones por odio (contra miembros de la comunidad LGTBIQ), desapariciones y asesinatos de dirigentes ecologistas y campesinos, desigualdades sociales, destrucción del ambiente, corrupción, etcétera, son alarmantes. Y aunque no resuelven sus propios problemas, sino que los agravan, son prestos para levantar el dedo acusador contra el gobierno venezolano. Y respecto al bloqueo económico, comercial y financiero impuesto por los Estados Unidos contra Cuba y ahora las agresiones económicas contra Venezuela hacen silencio absoluto.

Es en este contexto latinoamericano la política exterior del gobierno de Rafael Correa Delgado en relación con Cuba jugó un papel diferente al resto de presidentes, incluyendo los gobiernos progresistas. Las entrevistas y discursos de Correa muestran que su posición respecto a la política de los Estados Unidos hacia Cuba no es un asunto que responda a simpatías políticas o afinidades ideológicas, sino a cuestiones de principios de independencia, soberanía, autonomía y autodeterminación de los pueblos. No se puede ser democrático y aceptar o naturalizar la violación de los derechos humanos de toda una nación; es una violación que se hace en nombre de la democracia, la libertad y los derechos humanos. Como dice Hinkelammert muchas veces "los derechos humanos se transforman en justificación para la exterminación del otro" (2012, p. 111), o como lo ha expresado Gallardo "Internacionalmente, la acentuación de las agresiones y del bloqueo contra Cuba resulta geopolíticamente democrática" (2007, p. 53). 


\section{Cuba no es una democracia liberal}

En setiembre de 2007, ocho meses después de haber asumido la presidencia, fue entrevistado por Jorge Ramos periodista de Univisión (cadena de televisión estadounidense en español). Ramos le pregunta: "Señor Presidente, para usted ¿Fidel Castro es un dictador?" Correa responde:

Yo creo que Cuba tiene su forma de gobierno, no quiero inmiscuirme en los problemas internos de Cuba, pero creo que, claramente Fidel Castro ha jugado un rol muy importante en América Latina. Creo que tiene su forma de democracia; no es una democracia liberal estilo occidental, pero Cuba tiene elecciones. (Janer, feb. 2008)

Como se mencionó antes, este tipo de preguntas son las que buscan evaluar cuán "demócrata" es un político y, por lo tanto, cuán aceptado puede ser en el "mundo democrático", pero eso dependerá de la simpatía o el rechazo que asuma hacia la Revolución Cubana o hacia Fidel Castro. Para el entrevistador, en Cuba no existe "la" democracia, porque no existen partidos políticos:

Señor presidente usted tiene un doctorado, usted sabe que en Cuba hay una sola persona en el poder desde el ' 59 y hay un solo partido político, que el único candidato a la presidencia del país es Fidel Castro y ¿me está diciendo que en Cuba hay democracia? (Janer, feb. 2008)

El periodista apela al grado académico del entrevistado a la vez que pretende condicionar la respuesta "usted tiene un doctorado", es decir, usted por poseer un doctorado no puede decir que en Cuba hay democracia; o, porque usted tiene ese título universitario, entonces tiene que pensar como pienso yo: 'en Cuba no hay democracia'. Lo que hace el periodista es recurrir a la falacia de autoridad (ad verecundiam), al creer que, porque Rafael Correa tiene un título o prestigio (en este caso académico), entonces la opinión o conclusión no requiere de análisis ni razones, sino decir, lo que dice la mayoría: que 'en Cuba no hay democracia'. Pero Correa con su respuesta busca que el periodista entienda las limitaciones que tiene esa concepción de democracia:

Pero yo sé que también hay participación popular, hay organizaciones sociales, etcétera. Democracia es no tener elecciones necesariamente cada cuatro años; gobierno del pueblo y para el pueblo. ¡Cuidado sáquese [de la cabeza] el único esquema de la democracia formal, liberal, occidental. (Janer, feb. 2008)

Correa acababa de empezar su primer mandato como presidente de Ecuador, y contrario a lo que se acostumbra en esos casos: tener 'buenas relaciones' con el 
gobierno de los Estados Unidos y evitar posiciones contrahegemónicas, asume una perspectiva diferente. Defiende el sistema democrático cubano, elogia el papel que ha jugado Fidel Castro en América Latina y cuestiona la democracia burguesa, formal, liberal. En estos tres temas toma una posición opuesta a la de los Estados Unidos.

El 2008 cuando Correa iba camino a la Asamblea General de la ONU en Washington, se reunió con la colonia ecuatoriana radicada en Miami y, en esa ciudad fue invitado al programa A mano limpia del conductor Oscar Haza del Canal 41-America Tevé, perteneciente a la industria creada por los batistianos que huyeron de Cuba, dicho canal se caracteriza por emitir furibundas críticas al gobierno cubano. Correa respondió numerosas preguntas sobre Cuba, Ecuador, Bolivia, Fidel Castro, Evo Morales y Hugo Chávez; en la entrevista el conductor se vio muy mal, por los argumentos categóricos y la claridad de las respuestas de Correa, tanto así que, dijo que si volvían a transmitir el programa, se iba del canal (MovProyectoSur, jul. 2008).

Haza le pregunta por su opinión acerca de Fidel Castro y la respuesta de Correa es: "Creo que es un líder innegable de la región, que ha hecho historia." Y el periodista cuestiona: "No da la oportunidad de producir los cambios ahora". A lo que el entrevistado responde: “¿De quién es más la culpa, de Fidel Castro o de un bloqueo que dura 40 años? ¿Cuánto duraría cualquier país de Latinoamérica si tiene un bloqueo con el mercado más grande?" (MovProyectoSur, jul. 2008).

Se observa que, para Correa, cualquier cuestionamiento respecto a la situación de Cuba, debe tomar en cuenta primero, el nivel de responsabilidad (culpa) que tiene el bloqueo en ese país. En el homenaje a Fidel Castro tras su fallecimiento (25 noviembre de 2016), expresó: "Evaluar el éxito o fracaso del modelo económico cubano, haciendo abstracción de un bloqueo criminal de más de cincuenta años, es pura hipocresía" (Luigino, nov. 2016).

En ambos programas televisivos, Correa logró colocar su visión acerca del gobierno cubano, una posición opuesta al pensamiento de derecha, conservador, tradicional y contrarrevolucionario; temas como la democracia participativa, el bloqueo a Cuba y el rol de Fidel Castro en la historia latinoamericana son vetados por los grandes medios de comunicación más aún en Miami. La posición de Rafael Correa respecto a "la" democracia pone en cuestionamiento cierto fundamentalismo democrático.

Hasta aquí puede observarse que, con respecto a Cuba, como dice Ignacio Ramonet, el valor periodístico radica en someterse a la "censura del consenso", que repite lo que los grandes medios cantan a coro los mismos temas desde hace varios años: 
A la manera del adiestramiento pavloviano, el simple enunciado de la palabra Cuba desencadena así, automáticamente, en algunos países, una letanía de tópicos, repetidos ad nauseam por aquellos que han aceptado el axioma goebbelsiano según el cual una repetición equivale a una demostración. Ya nadie se toma el trabajo de verificar la versión única y bilateral de los hechos, que algunos se atreven a presentar-miseria del periodismo- como resultado de "revelaciones" o, más a la moda, de "investigaciones" (Ramonet, 2018, p. XV)

En este artículo podrá leerse que la observación anterior hecha por el periodista, respecto al proceder que tienen sus colegas en este caso respecto a Cuba es más evidente cuando se trata del periodismo ejercido por los grandes medios de comunicación capitalista.

\section{El derecho internacional y el bloqueo a Cuba}

La Cumbre de las Américas la integran 35 Estados americanos, y asisten a ella sus mandatarios o jefes de Estado. La primera cumbre se realizó en 1994 en Miami, y surgió una vez desaparecida la Unión Soviética; el objetivo de los Estados Unidos era promocionar a través de esas cumbres el Tratado de Libre Comercio (TLC) en los países que lo conforman. Ese objetivo sufrió un revés en la Cumbre de Mar de Plata el 2005, donde la presencia y participación de los presidentes Ignacio Lula Da Silva, Néstor Kirchner y Hugo Chávez fue vital para que en la Declaración Final se rechazara el propósito de Washington de imponer el TLC al resto de naciones. De ahí en adelante los Estados Unidos han tenido que lidiar desde dentro de la misma organización contra varios de los gobiernos de izquierda de la región, para intentar imponer sus intereses económicos.

Algunos meses antes de realizarse la VI Cumbre que tendría lugar en Cartagena de Indias, en abril de 2012, Rafael Correa había puesto en cuestión la importancia de estas, porque no abordaban temas importantes. En entrevista para la televisión española, la periodista le preguntó si asistiría a esa Cumbre, y él cuestionó su valor, porque trataban asuntos secundarios e ignoraban temas vitales, como el bloqueo que sufre Cuba:

Tenemos temor de que nuestros pueblos se cansen de que sus presidentes están en las cumbres y ellos continúan en los abismos; que vayamos para la foto, a conversar cosas triviales, a declarar nuestro amor por la democracia, por la libertad de expresión, por los derechos humanos; lugares comunes, frases clichés, y no se trate los problemas candentes, urgentes, intolerables en el siglo XXI, por ejemplo, el bloqueo a Cuba, que rompe todo el derecho interamericano, todo el derecho internacional. (Sucreranda, mar. 2012) 
Para él las Cumbres tendría importancia si trataran asuntos relevantes como el bloqueo a Cuba. Contrario a lo que se suele decir de Cuba, que es un Estado que viola los derechos humanos, Correa sostiene que es contra Cuba que se viola los derechos humanos al violarse el derecho internacional. Para él, no tiene sentido "declarar nuestro amor por los derechos humanos", si no se tratan problemas intolerables como el bloqueo que sufre Cuba.

En la historia de América Latina no ha existido antes de Correa, un presidente que cuestione el valor de esas Cumbres, más aún cuando estas han sido creadas y organizadas por los Estados Unidos y responden a sus intereses políticos y económicos en la región. Si el "dueño" del evento (de la Cumbre) es los Estados Unidos, y es este país el que tiene bloqueado a Cuba, entonces, es imposible que se trate el tema del bloqueo en la Cumbre (el "dueño" no lo permite). En la historia de las relaciones entre los gobiernos de los Estados Unidos y Cuba, no se conoce que el presidente de un tercer país haya intervenido con determinación para objetar el papel que ejerce los Estados Unidos. Al repreguntarle la periodista, "iqué tiene que pasar para que asista a la Cumbre?", responde:

Hablemos claro, la no participación de Cuba es por el bloqueo de los Estados Unidos. ¿Cómo América Latina en el siglo XXI, con todos los procesos de integración, todos los avances, todavía aceptamos esa clase de bloqueo? Eso es inaceptable, eso es impresentable. Cuando se habla eufemísticamente: "no hay consenso", es que Estados Unidos dijo no, y icómo podemos aceptar eso en el siglo XXI? Creemos que es intolerable que en una Cumbre de las América no participe un país americano como Cuba por el bloqueo de otro país americano. (Sucreranda, mar. 2012)

Correa hace una crítica directa al gobierno de los Estados Unidos por manipular a los países que integran la Cumbre; para él no es cierto que se diga que "no hay consenso"; se denomina consenso cuando hay un acuerdo o conformidad de todas las personas en algo. En este caso para que hubiera consenso, todas las delegaciones que pertenecen a la Cumbre debían haberse puesto de acuerdo, pero eso no sucedió; lo que existió fue una imposición de los Estados Unidos para frenar la participación de Cuba en la Cumbre. Aunque es una Cumbre de las Américas, Cuba país americano, es vetado de participar; pero es vetado, no porque haya habido un consenso para que no participe, sino porque el "dueño" del evento es quien le imposibilita participar. Con estas expresiones, Correa no solamente cuestiona el papel que ejerce el gobierno de los Estados Unidos, sino también objeta la actitud pasiva y sumisa de los otros gobiernos miembros de la Cumbre, incluidos los gobiernos de izquierda, que al igual que el resto, se dejan manipular. 
Aunque la periodista argumenta que hay otros mandatarios que asistirán a la Cumbre, como es el caso de Hugo Chávez quien es de izquierda y eso significaría que estaría de acuerdo con las condiciones que los Estados Unidos le pone a Cuba, Correa señala que esas son decisiones de ellos (de los otros gobiernos); pero que, para Ecuador, la decisión de no asistir a la VI Cumbre en caso de que Cuba no sea invitada, responde a principios y convicciones.

\section{Cuba y la democracia liberal occidental}

La ausencia de Correa a la VI Cumbre de las Américas dio mucho para hablar, y fue comentada en varios programas televisivos internacionales. En la entrevista que le hizo la cadena internacional CNN, el periodista intenta justificar la exclusión de Cuba al aducir que el gobierno del presidente Barack Obama estaba dispuesto a dialogar con las autoridades cubanas siempre y cuando haya flexibilidad en temas de derechos humanos y democracia. De esa forma el periodista coloca al presidente de los Estados Unidos en una posición de poder y con autoridad decisora; y por lo tanto, inmune a que se le objete sobre algo que él objeta a otros. Con ese propósito el periodista pone en la entrevista los temas de "democracia" y "derechos humanos". Estos temas han sido utilizados a nivel mediático cada vez que se habla de Cuba, con el objetivo de insinuar que en ese país socialista no se respetan los derechos humanos y no hay democracia (de esa forma, implícitamente, se dice que en los otros países capitalistas de América Latina, se respetan los derechos humanos y hay democracia). Al respecto Correa señala: "Maravilloso: entonces que eliminen Guantánamo que, es el mayor atropello a los derechos humanos y a la soberanía de un país”. Luego pregunta: "QQuién es el presidente de los Estados Unidos para convertirse en el árbitro del bien y el mal, y decidir qué es dictadura, y qué es democracia?" (Consuladosf, abr. 2012).

En América Latina y en Occidente en general, la palabra "democracia" se utiliza como sinónimo de democracia burguesa, liberal capitalista; es el Estado surgido a mediados del siglo XVIII en Occidente como proceso de emancipación en contra de las monarquías absolutas para establecer un sistema de gobierno que tuviera características como: poder votar y ser votado, proteger el derecho y existencia de grupos privados de poder económico (esto es esencial en la democracia burguesa liberal), poseer una constitución para limitar los diversos poderes y controlar el funcionamiento formal del gobierno, existencia de varios partidos políticos, libertad de expresión, libertad de prensa, libertad de asociación, protección de los derechos humanos, entre otras. Este es el referente elemental de democracia en el que la gente cree y, además, piensan que es la única; cualquier otra forma de gobierno, no es válida (ni democrática). Quienes defienden esta concepción de democracia le dicen al mundo que, "existe una sola manera de mirar y estar en el mundo: la 
capitalista democrática. Su éxito asegura su verdad y su belleza y, para algunos, la felicidad. Desde luego, se trata de un éxito contra otros" (Gallardo, 2007, p. 44). En la 'primera carta a las izquierdas', Boaventura de Sousa Santos señala que, "el capitalismo concibe a la democracia como un instrumento de acumulación; si es preciso, la reduce a la irrelevancia y, si encuentra otro instrumento más eficiente, prescinde de ella" (Página 12, párr. 6).

Los oligopolios de la comunicación difunden y defienden "la" democracia (burguesa) como exclusiva y verdadera, y muchas veces naturalizan esa concepción; por eso el periodista de $\mathrm{CNN}$ cree que Cuba no es una democracia (la gran mayoría de latinoamericanos cree lo mismo), de ahí que el reportero pregunte: "ipara qué sirvió una de esas pocas Cumbres donde sí hubo un documento firmado que fue la Carta Interamericana de Democracia que estipula un poco hacia dónde va la democracia en el continente?" Pero la visión de Correa es distinta, y por eso cuestiona: "iY la democracia liberal occidental quién dijo que es el único modelo de democracia?" (Consuladosf, abr. 2012).

La democracia que practica Cuba es tan "extraña" que, por ejemplo desde el 13 de agosto al 15 de noviembre de 2018, un total de 8945521 cubanos (los votantes son nueve millones) han participado en los debates efectuados en los barrios, centros estudiantiles y de trabajo, dentro y fuera del territorio nacional, respecto al Proyecto de Constitución de la República en Cuba (Cubadebate, 2018, párr. 1). En ese proceso de consulta popular se realizaron: 133681 reuniones, de ellas: 79 947 de la población, 45452 de colectivos de trabajadores, 3441 de campesinos, 1585 de estudiantes universitarios y 3256 de estudiantes de la enseñanza media. Se realizaron 1706872 intervenciones, de ellas, 783174 propuestas, 666995 modificaciones, 32149 adiciones, 45548 eliminaciones y 38482 dudas (Consejo de Estado, dic. 2016). Se trató de un amplio proceso de consulta popular, en el que la ciudadanía expresó libremente sus opiniones sobre el contenido del Proyecto, y modificó el $60 \%$ de los artículos; es ese el carácter profundamente democrático de la Revolución, en donde las principales decisiones que definen la vida del país se elaboran con el aporte de todo el pueblo cubano (Granma, 2018). Este tipo de participación popular no existe en ningún otro país del mundo, en las llamadas democracias burguesas (occidental, liberal, formal); no se conoce de un referéndum como el que ha llevado a cabo Cuba en el tema de la Constitución, que ha sido convocado por las autoridades comunistas cubanas, empezando por el primer secretario del Partido Comunista, el General de Ejército Raúl Castro, hasta el ciudadano común de a pie más sencillo. 


\section{Los Estados Unidos y los derechos humanos en Guantánamo}

Correa también cuestiona el hecho de que los Estados Unidos se presente como modelo en la defensa de los derechos humanos, porque su gobierno ejerce una de las mayores violaciones contra otros países, como es el bloqueo contra Cuba, que transgrede todas las normas internacionales:

Pero es claro que es un atropello al derecho internacional, a los derechos humanos, a la soberanía de Cuba, condenado decenas de veces por las Nacionales Unidas, por la inmensa mayoría de las naciones; es un bloqueo criminal, de la economía más grande del mundo, por más de casi medio siglo ya a Cuba. Eso sí es concreto, evidente, urgente. Entonces creo que el primer paso es levantar ese bloqueo criminal...es la doble moral, se pasan hablando de derechos humanos... ¿Qué peor atentado a los derechos humanos que las torturas en Guantánamo, tener una base extranjera en un país soberano como Cuba y por supuesto el criminal bloqueo? (Consuladosf, abr. 2012)

La Carta Interamericana de Democracia es un instrumento de la OEA creada el 2001, cuyo objetivo principal es fortalecer y preservar la institucionalidad democrática en la región. Si se toma como referencia el Capítulo II "La democracia y los derechos humanos", sus cuatro artículos (del 7 al 10) ponen en entredicho la defensa y el respeto a los derechos humanos por parte del gobierno de los Estados Unidos hacia sus propios ciudadanos y hacia otras naciones. Y a eso se agrega las violaciones a los derechos humanos de las personas detenidas en Guantánamo desde abril de 2002, cuando el entonces presidente George W. Bush mandó crear esos campos de detención. Al respecto, después de dieciséis años en enero de 2018, el relator especial de la ONU para la Tortura, Nils Melzer, condenó el 'ejemplo' que Estados Unidos le da al mundo al mantener Guantánamo, una cárcel donde se realizan toda clase de abusos a los Derechos Humanos (Telesur, 2018).

No es un asunto menor, sobre todo en tiempos en que los grandes medios de comunicación osan tener la verdad de los hechos y emiten mensajes unidireccionales y homogéneos, que en un set televisivo internacional como CNN, donde siempre difunden información contra la Revolución Cubana, que un presidente latinoamericano defienda la soberanía y autonomía de Cuba, y señale a los Estados Unidos uno de los países más poderosos del mundo, de ser violador de derechos humanos y cuyos gobiernos están siempre acostumbrados a imputar a otros, pero no a aceptar críticas de este tipo. 


\title{
La OEA y la revolución cubana
}

En entrevista con Canal Capital de Colombia realizada después de la VI Cumbre, el periodista aborda el mismo tema (de la ausencia de Correa a la Cumbre), pero relaciona la decisión de Correa de no asistir, con la idea de la soberanía latinoamericana. Le consulta que "si por darse valor como latinoamericanos, es que Ecuador decide no asistir a la Cumbre y por eso dijo que: ¡si no va Cuba, no va Ecuador!" Correa explica que, la posición de Ecuador de condicionar su presencia en la Cumbre es porque hay organizaciones internacionales que actúan con una doble moral:

\begin{abstract}
Al Chile de Pinochet no lo expulsaron, para que vea la doble moral, pero a Cuba la expulsaron. Y ahí usted ve otra contradicción, la OEA con sede en Washington, el país del bloqueo a Cuba, bloqueo que rompe toda la carta fundacional de la OEA, todo el derecho internacional y los derechos humanos. Y también la Comisión de los Derechos Humanos tiene la sede en Washington. Toda esta clase de doble moral ya no puede ser tolerada en América Latina. ¿Por qué la Cumbre de las Américas sin Cuba? ¿Acaso Cuba no está en las Américas? Entonces Ecuador dijo si no va Cuba, no vamos nosotros. En la próxima Cumbre deberá estar Cuba, si está Cuba, estaremos. (Secom, ago. 2014)
\end{abstract}

Para Correa, la doble moral no debe ser tolerada en América Latina. Se refiere, concretamente, al papel que ha desempeñado la OEA en la historia de América Latina que, por un lado expulsó en 1962 a Cuba del organismo a raíz del triunfo de la Revolución en 1959 al tomar luego el rumbo socialista, pero nunca excluyó a Chile, cuya dictadura (1973-1990) encabezada por Augusto Pinochet, desapareció, torturó y asesinó a miles de personas. En todos los años de su existencia, la OEA nunca se ha manifestado en contra del bloqueo a Cuba.

La exclusión de Cuba de la OEA es una forma de oposición de dicho organismo a los esfuerzos de integración regional; esa exclusión también ha sido normalizada y ningún país cuestiona esa situación. Siempre han existido esfuerzos por parte de algunas naciones a favor de la unión de los pueblos, pero la OEA con su posición hacia Cuba, ha mostrado lo contrario; la OEA no es la organización autorizada para promover ninguna integración de los pueblos latinoamericanos.

Desde finales de los años noventa y los primeros tres lustros del siglo XXI, por el impulso de los gobiernos de izquierda, se gestaron y crearon algunos proyectos de integración regional, que se convirtieron en foros y espacios alternativos a la OEA, ellos fueron la UNASUR y la CELAC. 
El 2004, en la reunión de presidentes de América del Sur, realizada en Cuzco, Perú, se creó la Comunidad Suramericana de Naciones (CSN), que después daría paso a la conformación de la Unión de Naciones Suramericanas (UNASUR). La CSN nació para integrar procesos regionales desarrollados por el Mercosur y la Comunidad Andina. En el 2005, en Brasilia y en el 2006 en Cochabamba, Bolivia, los Jefes de Estado de los países miembros establecieron un plan estratégico para consolidar una agenda común en la región. El 2007, durante la Cumbre Energética Suramericana, que se llevó a cabo en la Isla Margarita, Venezuela, los jefes de Estados cambiaron el nombre de Comunidad Suramericana de Naciones a Unión de Naciones Suramericanas: UNASUR. Y el 2008, se aprobó el Tratado Constitutivo de la Unión de Naciones Suramericanas, en el cual se designó como sede permanente de la Secretaría General a Quito, capital del Ecuador; y del Parlamento a Cochabamba, Bolivia. El objetivo general de UNASUR es construir un espacio de integración en lo cultural, económico, social y político, que respete siempre la realidad de cada nación; además, tiene veintiún objetivos específicos, los cuales permitirían que las naciones del sur del continente logren integrarse, y juntas mejorar sus condiciones de vida en todos esos aspectos (UNASUR, 2008).

En los últimos años UNASUR ha vivido reveses a su proyecto inicial de integración, porque seis países decidieron suspender su participación (Argentina, Brasil, Chile, Colombia, Perú y Paraguay), todos estos son gobiernos de derecha; y a esto se sumó, la idea del presidente Lenin Moreno de Ecuador en julio de 2018, de solicitarle a UNASUR la devolución del edificio que se encuentra en Quito, con el argumento de que le dará un mejor destino (aunque no dijo cuál es ese destino). Es evidente que para Moreno buscar la integración de los países del sur no es un buen destino. Desde que él asumió la presidencia de Ecuador en mayo de 2017, traicionó a quienes votaron por él y al partido Alianza País del cual fue candidato; se desentendió totalmente del plan de gobierno prometido, y asumió la agenda de gobierno de la derecha neoliberal, que fue derrotada en las urnas; por eso no es difícil entender su distanciamiento de la UNASUR. La perspectiva de un gobierno de Alianza País y de Rafael Correa siempre fue la de promover la integración regional.

Lo que se muestra es que no solo el gobierno de los Estados Unidos está en contra de la integración regional, sino también los gobiernos latinoamericanos de derecha, cuyos presidentes son sumisos a Washington, a pesar de que saben que negociar de forma aislada o individual con los Estados Unidos significa enfrentar el poder en condiciones asimétricas y perder. Mientras que si se actuara en bloque, se lograría transmitir los valores latinoamericanos al mundo y defender los intereses colectivos de la región. 
Por su parte la Comunidad de Estados Latinoamericanos y Caribeños (CELAC) nace el 2010, como un mecanismo intergubernamental de diálogo y concertación política, compuesta por los treinta y tres países de América Latina y el Caribe. Surgió con el compromiso de avanzar en el proceso de integración de la región, para hacer un equilibrio entre la unidad y la diversidad política, económica, social y cultural de sus 600 millones de habitantes. Desde sus inicios ha buscado profundizar el diálogo entre todos los países que lo conforman, en temas como el desarrollo social, la educación, el desarme nuclear, la agricultura familiar, la cultura, las finanzas, la energía y el medio ambiente. También ha promovido que la región se asuma a sí misma como una comunidad de naciones, capaz de dialogar y de buscar consensos en temas de interés común. Por eso se constituyó en la voz unificada de la región en temas de consenso; y ser el único interlocutor que promueva una voz concertada de la región en la discusión de los grandes temas globales, con el objetivo de buscar una mejor inserción y proyección de la región en el ámbito internacional (CELAC, 2017).

La participación de Rafael Correa en el desarrollo y fortalecimiento de ambos organismos regionales durante los años que fungió como presidente de Ecuador fue ardua; trató de hacer entender a sus miembros, que la única manera de sobrevivir en una economía de mercado que además de ser desigual es inmoral, era negociando en bloques (RT en español. Oct. 2013). Aunque esa propuesta es real, necesaria y viable, sin embargo, no es practicada por dichos organismos; por el contrario, algunos presidentes de derecha, hacen lo posible por oponerse y debilitar los pequeños esfuerzos de conformación de bloques.

\section{El derecho internacional y el bloqueo a Cuba}

El 2014 se llevó a cabo en Cuba la II Cumbre de la CELAC, presidida por Raúl Castro. En La Habana, Correa ofreció una entrevista amplia a RT en Español. La periodista le dice que la celebración de la Cumbre en Cuba ha sido aplaudida por todas partes, sin embargo, también ha despertado críticas por los cubanos que viven en los Estados Unidos, quienes lo ven como intento de legitimar el gobierno de Raúl Castro ante la comunidad internacional. A esas críticas Correa responde " $\mathrm{Si}$ los perritos ladran es señal de que avanzamos, que avanza la Patria Grande, que se construye esa Patria Grande", y defiende que la Cumbre se haya realizado en Cuba:

Es emblemático que Cuba haya presidido la Comunidad de Estados Latinoamericanos y del Caribe. Recuerde que Cuba estuvo excluida injustamente, intolerablemente de la OEA por imposición de los Estados Unidos y, que ahora presida esta Comunidad de Estados Latinoamericanos y del Caribe, es un signo de cambio de época, nuevos cambios que vive Nuestra América de justicia, de dignidad, de liberación, de no tolerar 
más neocolonialismos. Y eso es lo que significa Cuba para América Latina y a nivel mundial. Un país pequeño, inmenso en dignidad, que ha resistido medio siglo un bloqueo criminal ilegitimo que atenta contra toda la carta fundacional de la OEA, contra el derecho internacional, contra los derechos humanos; y todo el mundo hacia mutis por el foro, la propia OEA. (RT en Español, ene. 2014)

A la pregunta ipor qué la II Cumbre de la CELAC se hace en Cuba?, Correa responde que se debe a los "nuevos cambios que vive Nuestra América de justicia"; esos nuevos cambios lo constituyen la presencia y participación de los gobiernos progresistas que fueron los arquitectos de esa organización, que a diferencia de la OEA que tiene un "dueño" y excluye a Cuba, en la CELAC Cuba tiene los mismos derechos y deberes como cualquier miembro. Para Correa, que Cuba presida la CELAC es una muestra de "dignidad, de liberación, de no tolerar más neocolonialismos".

El hecho de que Raúl Castro se convirtiera según la rotación en presidente pro tempore de la CELAC, fue una victoria histórica de Cuba. Al respecto Leonov dice:

Por más de medio siglo, Estados Unidos ha estado empeñado en aislar y boicotear a la Isla de la Libertad y ahogar a la Revolución Cubana por todas las vías: terror, sabotaje, intervenciones militares y guerra económica. A pesar de ello, la mayor de las Antillas se convertía en líder de las naciones vecinas hermanas, rodeada por las simpatías de los pueblos, que siempre estuvieron junto a ella, y de la inmensa mayoría de los gobiernos. (2015, p. 352)

Para Correa, el bloqueo de los Estados Unidos contra Cuba, es un bloqueo criminal que viola todo el derecho internacional y todos los derechos humanos. En toda la entrevista realizada para RT en Español, no se encuentra que la crítica del mandatario al bloqueo de los Estados Unidos sea porque simpatice con el sistema político socialista cubano, sino porque la propia carta fundacional de la OEA no permite este tipo de abusos; y el país que ejerce el bloqueo es el propio fundador y promotor de la OEA: los Estados Unidos. Es decir, para rechazar el bloqueo que sufre Cuba, no es necesario ser socialista o marxista, basta con seguir los principios de la misma OEA; como se dijo antes, todos los años en la Asamblea General de la ONU el proyecto de resolución presentado por Cuba, demandando el fin del bloqueo, obtiene un respaldo mayoritario y contundente, con las excepciones de los Estados Unidos e Israel. Para oponerse al bloqueo nada tiene que ver si se es partidario o no de la Revolución Cubana, estar contra el bloqueo es un asunto de principios, es ser consecuente con el respeto al derecho internacional. 
Correa al asumir una postura crítica hacia los Estados Unidos, exigiendo respeto al derecho internacional, rompe con la historia tradicional de la conducta de otros presidentes de América Latina respecto a la relación de los Estados Unidos hacia Cuba; dice que, contra ese abuso de poder "todo el mundo hacia mutis por el foro, la propia OEA".

En esa II Cumbre de la CELAC, Correa no tuvo reparos en cuestionar el papel desempeñado por la OEA en América Latina y contra Cuba. En su discurso expresó:

¿Cuál es el rol de la OEA en nuestra Nueva América? Que no solo permite, sino que incluso tiene su Sede en el país del criminal bloqueo a Cuba, que rompe toda la Carta Fundacional de la OEA, el Derecho Internacional y los Derechos Humanos. Parafraseando a Fidel, bien podría llamarse la OEA el Ministerio de las Colonias. (Cubahoy, ene. 2014)

La crítica que hace a la OEA por no apegarse al derecho internacional y por ser cómplice del bloqueo contra Cuba es un hecho sin precedentes en la historia de los presidentes de América Latina. Fidel Castro y Raúl Roa (diplomático cubano) fueron quienes en enero de 1962 calificaron a la OEA de "Ministerio de Colonias Yanqui"

\section{La dignidad de Cuba frente a la OEA}

En abril de 2015 se realizó la VII Cumbre de las Américas en Panamá, y como se explicó antes, Rafael Correa había anunciado que si Cuba no era invitada, entonces Ecuador no asistiría. El mensaje de Correa tuvo eco en varios de los gobiernos progresistas de la región, por lo que el presidente de Panamá temía que otros presidentes se sumaran a esa idea especialmente los gobiernos pertenecientes al ALBA, y la Cumbre no se realizaría; por lo que se vio en la obligación de hacerle la invitación formal al gobierno de La Habana. Era la primera vez que Cuba asistía a este tipo de cumbres, donde el "dueño" del evento había sido siempre el gobierno de los Estados Unidos; pero esta vez, ya no tenía el poder de otros años debido a la presencia de los gobiernos progresistas para vetar a Cuba. La portavoz del Departamento de Estado Norteamericano, Jen Psaki señaló implícitamente que la asistencia de Cuba a la cumbre sería una burla a la Carta Democrática Interamericana. A pesar de esas declaraciones, después de más de cinco décadas los representantes de los gobiernos de Estados Unidos y de Cuba se encontraron en un foro. En esa Cumbre Rafael Correa fustigó el bloqueo y destacó la presencia de Cuba: 
Hoy asistimos a un evento histórico. En un triunfo irrestricto de la dignidad, la soberanía y la solidaridad entre los pueblos, acogemos a la hermana República de Cuba como un miembro de pleno derecho de este foro del que nunca debió ser excluida.

Sin embargo, nuestra alegría no puede ser completa, aún queda por extirpar el inhumano e ilegal bloqueo contra Cuba. También está pendiente la devolución a Cuba del territorio ocupado de Guantánamo. (RT, abr. 2015)

Ante la presencia de los jefes de Estado y de Gobierno de los Estados miembros del hemisferio, incluido el presidente Barack Obama, Correa hizo un repaso de la historia latinoamericana y señaló la responsabilidad que han tenido las distintas administraciones estadounidenses en los golpes de Estado y en el apoyo a las dictaduras en América Latina, que so pretexto de luchar por la democracia, los derechos humanos, la libertad y contra el comunismo, ejercieron ilegales intervencionismos en muchos países.

Paralelo a la VII Cumbre de Jefes de Estado se realizó también la Cumbre de los Pueblos, este es un encuentro internacional de representantes de movimientos sociales y de organizaciones políticas que comparten un pensamiento progresista y antineoliberal, y cuestionan las políticas que aplica el gobierno de los Estados Unidos en los países latinoamericanos y caribeños; ahí sientan posiciones sobre los problemas sociales, y buscan presentar reclamos a los diferentes gobiernos. A esa cumbre fue invitado Rafael Correa, donde expresó que, la VII Cumbre de las Américas fue histórica porque por primera vez estuvieron todos, como expresión de una América Latina más soberana y más digna, la cual no tolerará más injerencia, ni intervencionismo, ni unilateralismo y, jamás volverá a ser patio trasero de nadie. Saludó la presencia de Cuba y felicitó el acercamiento entre La Habana y Washington, pero advirtió contra las visiones hegemónicas por parte de los Estados Unidos, porque se acerca a Cuba como si estuviera haciéndole un favor:

Aquí no hay favores señores, aquí hay justicia, eso se lo ha ganado el pueblo cubano después de décadas de dignidad, de lucha, de no haberse sometido al imperio más grande de la historia. Aquí no hay favores, por el contrario tendrían que pedir disculpas, resarcir a Cuba por todo el daño que le han hecho. Reconocer la injusticia, no hablar de concesiones...hay que respetar la soberanía de los países, hay que respetar el derecho internacional, hay que respetar la autodeterminación de los pueblos, hay que respetar la misma Carta de la OEA que la invocan a su conveniencia. iQue viva Cuba, libre, soberana, digna, revolucionaria! (Telesur, abr. 2015)

En este mensaje a la Cumbre de los Pueblos Correa cuestionó la actitud y visión hegemónicas del gobierno de los Estados Unidos por creer que tiene más derechos 
que el resto de los países, o porque ve y trata a los demás -en este caso a Cuba-, como si fueran naciones sin derecho a su autodeterminación, soberanía e independencia. En este caso, Correa se alinea a uno de los principios que siempre ha sostenido la Revolución Cubana: Relacionarse con otros países cualesquiera que sean, en igualdad de condiciones, donde se respete la independencia de Cuba, sobre las bases de igualdad, reciprocidad, no injerencia y respeto mutuo.

\section{Cuba, solidaridad y modestia}

Al final de su gobierno, en mayo de 2017, Correa viajó a Cuba a recibir el doctorado Honoris Causa de la Universidad de La Habana; durante su estadía fue entrevistado por la televisión cubana. El mandatario recordó que durante el tiempo que él estuvo como presidente de Ecuador (2006-2017), en las universidades de Cuba se habían graduado más de dos mil médicos ecuatorianos y, todavía en ese año (2017) había 400 ecuatorianos que estudiaban el posgrado. Y le dice al periodista que hacia la Revolución solo tiene gratitud y admiración, porque Cuba les ha ayudado a preparar estudiantes, formándolos en ciencia y conciencia. Subraya que "la solidaridad es lo que define a Cuba":

Ese talento humano estoy muy contento que venga a formarse acá, sobre todo a nivel de médicos, porque en Cuba no reciben sólo una formación en ciencia, también reciben una formación en conciencia, en compromiso. Entonces son extraordinarios profesionales pero muy comprometidos socialmente. Además, ahora ayudamos nosotros con becas, y se ha flexibilizado un poco la selección de chicos que vienen a Cuba, pero antes eran becas cubanas, y la embajada cubana en Ecuador escogía a los chicos de los pobres entre los pobres, indígenas, amazónicos. ¡Cuántos amazónicos tenemos estudiando en Cuba que antes no pensaban llegar a la Universidad! Cuba ha hecho un trabajo extraordinario en ese sentido. (Cubadebate, may. 2017)

Correa saca a la luz en esa entrevista una de las prácticas de solidaridad internacionalista que desarrolla el gobierno cubano, al otorgar formación médica a estudiantes provenientes de otros países.

Además de que Cuba no exhibe lo que hace (Bravo, 2016), el bloqueo ejercido por los Estados Unidos a través de los medios de información logra ocultar e invisibilizar esas prácticas revolucionarias. En esa entrevista el presidente ecuatoriano expresa con total libertad su opinión favorable sobre la Revolución Cubana (como lo ha hecho en otros escenarios), y muestra gratitud, cariño y admiración hacia el pueblo de la Isla, y lo coloca como ejemplo de rebeldía, resistencia y dignidad, frente a un bloqueo que califica una vez más, de criminal: 
Me molesta mucho cuando dicen ¡Uy el modelo económico y social de Cuba! ¡Miren los problemas que tiene! Y se olvidan de un "pequeño" bloqueo criminal de más de medio siglo, que ningún país capitalista de América Latina resistiría ni seis meses. Cuando acabe ese bloqueo criminal que atenta contra todas las reglas de derecho internacional, el derecho interamericano y los derechos humanos, verán cómo se dispara Cuba, será indetenible porque tiene lo más valioso: talento humano. ( $\mathrm{Cu}$ badebate, may. 2017)

En esa intervención él fija tres aspectos fundamentales con respecto a la Revolución Cubana, los cuales están estrechamente relacionados: 1) no se puede analizar el modelo económico y social de Cuba y sus resultados, sin tomar en cuenta el bloqueo impuesto por los Estados Unidos hace casi seis décadas; 2) el bloqueo es una violación a los derechos humanos de toda una nación y a todas las reglas del derecho internacional, y 3 ) a pesar del bloqueo, Cuba cuenta con una población preparada, que le permitirá despegar humana y socialmente, una vez que el bloqueo sea levantado.

\section{Conclusiones}

Al principio se había anunciado que el objetivo de este artículo era presentar el papel asumido por el entonces presidente Rafael Correa respecto a la relación que tiene el gobierno de los Estados Unidos con Cuba, a partir de los temas de la democracia y los derechos humanos. En los diez videos estudiados el exmandatario ecuatoriano es el protagonista principal; en los siete que son de entrevistas, los periodistas hombres y mujeres le interrogan con alguna agudeza y suspicacia sobre dichos temas; y en los otros tres, él diserta sin ninguna mediación, también sobre esos contenidos.

Encontramos que para Correa, cualquiera que quiera hablar, estudiar o referirse a la relación entre el gobierno de los Estados Unidos y el gobierno de Cuba, no debe desconocer que se trata de una relación asimétrica entre ambos países, no solo porque es entre un país del llamado Primer Mundo y otro del Tercer Mundo, sino porque lo que media desde hace casi sesenta años entre ellos es un bloqueo económico, comercial y financiero cruel y criminal, que atenta y viola los derechos humanos de todo un pueblo y nación, e irrespeta todos los principios y tratados del derecho internacional, incluidos aquellos en los que se sostiene la OEA y los predica, organización que incluso es afín a los intereses económicos y políticos de los Estados Unidos en América Latina. De manera que, para hacer un juicio respecto a los derechos humanos en Cuba, debe considerarse ese "pequeño" detalle: el bloqueo que ha provocado perjuicios cuantificables por más de 134 mil 499 millones 800 mil dólares a Cuba en estas casi seis décadas. 
En todas las intervenciones de Correa aquí estudiadas, él devela, cuestiona y condena la naturalización que la comunidad internacional ha hecho del bloqueo; este se acepta sin más, excepto cuando cada año, por amplia mayoría en la Asamblea General de la ONU, todas las delegaciones (menos Israel y los Estados Unidos) votan por el fin de este mismo.

Contrario a lo que piensan quienes le entrevistaron así como la mayoría de los latinoamericanos, Correa sostiene que el sistema político cubano es democrático; no es una democracia burguesa, liberal, capitalista, formal y occidental, sino, una democracia socialista, participativa, con elecciones libres y periódicas; en esa sociedad la población participa y asume responsabilidades en diferentes órganos de decisión popular; por eso sostiene él que, no es correcto juzgar la democracia socialista cubana con parámetros de la democracia burguesa, capitalista y liberal. Y es desde esa democracia socialista donde Cuba se ha mostrado solidaria con otros pueblos del mundo, por ejemplo, al otorgar becas a jóvenes de otros países para que estudien medicina en Cuba.

El estudio revela que la posición de Correa en defensa de Cuba es asumida a partir del derecho interamericano y del derecho internacional; y que, para cuestionar, oponerse y rechazar el bloqueo, no se necesita ser socialista o comunista, lo que se necesita es estar de acuerdo con el derecho de los pueblos a su autodeterminación, independencia y autonomía.

\section{Bibliografía}

Betto, F. (4 de enero de 2019). La revolución cubana cumple 60 años. Cubadebate. Recuperado de http://www.cubadebate.cu/especiales/2019/01/04/la-revolucion-cubana-cumple-60-anos/\#. XDAF2s2jnIU

Bravo, A. (2016). El ADN de la Revolución y los tres médicos cubanos. Recuperado de http:// www.rebelion.org/noticia.php?id=211722

Castro, R. (1 de enero de 2019). Tras 60 años de luchas, sacrificios, esfuerzos y victorias, vemos un país libre, independiente y dueño de su destino. Granma. Recuperado de http://www. granma.cu/discursos-raul/2019-01-01/tras-60-anos-de-luchas-sacrificios-esfuerzos-y-victoriasvemos-un-pais-libre-independiente-y-dueno-de-su-destino-01-01-2019-23-01-14

CELAC. (2017). ¿Qué es la CELAC? Recuperado de http://www.sela.org/celac/quienes-somos/ que-es-la-celac/

Consejo de Estado. (22 de diciembre de 2018). Intervención de Homero Acosta en la Asamblea Nacional, sobre los principales cambios de la Constitución a 
partir de la consulta popular. Recuperado de http://www.granma.cu/cuba/2018-12-22/ un-texto-enriquecido-con-el-aporte-del-pueblo-22-12-2018-01-12-24

Cubadebate. (2018). Informe de Cuba. Recuperado de http://media.cubadebate.cu/wp-content/ uploads/2018/08/informe_de_cuba_sobre_el_bloqueo_2018.pdf

Cubadebate. (12 de mayo de 2017). Entrevista a Rafael Correa en La Habana, Mundo Latino, mayo 2017. [Video]. Recuperado de https://www.youtube.com/watch?v=XjXoayTR23E

Cubadebate. ( 2 de noviembre de 2018). Más de 7 millones de cubanos han participado en el debate constitucional. Recuperado de http://www.cubadebate.cu/noticias/2018/11/02/ mas-de-7-millones-de-cubanos-han-participado-en-el-debate-constitucional/\#.W95hZeKjnIU

Cubahoy. (28 enero de 2014). Intervención de Rafael Correa en II Cumbre de la CELAC. [Video]. Recuperado de https://www.youtube.com/watch?v=88D_PYRdluw

Chávez, H. (2006). Discurso del presidente de la República Bolivariana de Venezuela, Hugo Chávez Frías en la sexagésima primera Asamblea General de la Organización de Naciones Unidas. [Video]. Recuperado de https://www.panorama.com.ve/hugochavez/Discursos-memorables-Aqui-huele-a-azufre-20150720-0083.html

El Caminante. (2018). Cuba posee el mejor sistema educativo de América Latina, asílo reconoció el Banco Mundial. El Caminante. Recuperado de https://elcaminantehn.com/2018/12/08/ cuba-posee-el-mejor-sistema-educativo-de-america-latina-asi-lo-reconocio-el-banco-mundial/?fbclid=IwAR161ha3C_EAaNPVr-GxOfv5dMzOR5iSabBg_z7HLENovDIyRA-mNQlKM-4

Escalante, F. (2018). La Guerra Secreta. Operación ZR/Rifle. La Habana: Editorial de Ciencias Sociales.

Gallardo, H. (2007). Democratización y democracia en América Latina. Bogotá: Ediciones desde abajo.

Hinkelammert, F. (2011). Lo indispensable es inútil. Hacia una espiritualidad de la liberación. San José Costa Rica: Editorial Arlekín.

Janer. (3 de febrero de 2008). Según Correa en cuba no hay dictadura. [Video]. Recuperado de https://www.youtube.com/watch?v=X_K53J0ocKk

Leonov, N. (2015). Raúl Castro. Un hombre en revolución. La Habana, Cuba: Editorial Capitán San Luis.

Luigino. (29 de noviembre de 2016). Discurso de Rafael Correa en La Habana, homenaje a Fidel Castro tras su fallecimiento. [Video]. Recuperado de https://www.youtube.com/ watch? $=\mathrm{Je} 8 \mathrm{C} 30 \mathrm{Ncp} 9 \mathrm{~A}$ 

political relations between the United States and Cuba

MovProyectoSur. (20 de julio de 2008). Rafael Correa entrevista con periodista de Miami [Video]. Recuperado de https://www.youtube.com/watch?v=R_q0LHVS4hM

Ramonet, I. (2018). Cien horas con Fidel. Conversaciones con Ignacio Ramonet. 4ta edición. La Habana Cuba: Editorial de Ciencias Sociales, Oficina de Publicaciones del Consejo de Estado.

RT en español. (29 de octubre de 2013). Rafael Correa a RT: "El imperialismo del siglo XXI son los dólares”. [Video]. Recuperado de https://www.youtube.com/watch?v=RzGfo13W_Sk\&t=1431s

RT en Español. (30 de enero de 2014). Entrevista en exclusiva con Rafael Correa, presidente de Ecuador. [Video]. Recuperado de https://www.youtube.com/watch?v=f56P5hC008A

RT en Español. (11 de abril de 2015). Discurso completo de Rafael Correa en la VII Cumbre de las Américas. [Video]. Recuperado de https://www.youtube.com/watch?v=WrBAVwsL9wQ

Santos, B. (2011). Primera carta a las izquierdas. Página 12. Recuperado de https://www.pagina12. com.ar/diario/elmundo/4-177226-2011-09-21.html

SECOM. (8 de agosto de 2014). Entrevista del presidente Rafael Correa en Canal Capital de Colombia. [Video]. Recuperado de https://www.youtube.com/watch?v=JpA4CxsadSk

Sucreranda Hugo Chávez Venezuela. (19 de marzo de 2012). Rafael Correa vapulea a Anita Pastor en Los Desayunos de TVE. HRW cartel de Sinaloa. Bancos. Cuba. [Video]. Recuperado de https://www.youtube.com/watch?v=zMQEvZ4itoo

Sucreviral. (14 de diciembre de 2014). Rafael Correa vapulea al antichavista Jordi Évole del canal derechista La Sexta. Régimen de España. [Video]. Recuperado de https://www.dailymotion. $\mathrm{com} /$ video/x2cklgp

Telesur. (11 de abril de 2015). Rafael Correa: Jamás volveremos a ser el patio trasero de nadie. [Video]. Recuperado de https://www.youtube.com/watch?v=UbLqiaoyfrE

Telesur. (11 de enero de 2018). Guantánamo, 16 años de violaciones a DD.HH. que siguen impunes. Recuperado de https://www.telesurtv.net/news/Guantanamo-16-anos-de-violaciones-a-DD.HH.-que-siguen-impunes-20180111-0001.html

UNASUR. (2008). ¿Cómo funciona UNASUR? Recuperado de https://www.unasursg.org/es

U.S. Department of State. (12 de junio de 2010). Secretary Clinton Joint Press Conference With Ecuadorian President. [Video]. Recuperado de https://www.youtube.com/ watch?v=QebunDifiLk 